Nikolay S. Kasimov ${ }^{1}$, Tatyana V. Kotova ${ }^{2}$, Vladimir S. Tikunov ${ }^{{ }^{*}}$

${ }^{1}$ Dean, Faculty of Geography, M.V. Lomonosov Moscow State University. Russia,

119991, Moscow, Leninskiye Gori, 1. Tel: (+7-495) 939-22-38; fax: (+7-495) 932-88-36;

E-mail: secretary@geogr.msu.ru

${ }^{2}$ Faculty of Geography, M.V. Lomonosov Moscow State University. Russia, 119991,

Moscow, Leninskiye Gori, 1. Tel: (+7-495) 939-22-38; Fax: (+7-495) 932-88-36;

E-mail: tkot@geogr.msu.su

${ }^{3}$ Faculty of Geography, M.V. Lomonosov Moscow State University. Russia, 119991,

\title{
THE ENVIRONMENTAL ATLAS - AN IMPORTANT STAGE IN ARCTIC RESEARCH
}

\begin{abstract}
In the present and future development of the Arctic region, much attention is and will be given to environmental problems. Along with social and economic, these issues are the most essential components of a model of sustainable development of the region. Cartographic studies implemented in the atlas format (either printed or electronic) provide the most comprehensive, adequate, and complete representation of the Arctic environment. Such Atlas will serve as a basis for creation of the Atlas Information System "Environment of the Arctic". The material presented herein describes the purpose of the Atlas and its scientificmethodological principles. The Atlas includes 7 parts (thematic blocks) and over 18 sub-blocks that characterize natural and anthropogenic factors of formation of the natural environment, the state of the natural environment, population ecology, and efforts of Russian and international organizations aimed at optimization of the regional environment. The material also presents methodological features of the Atlas and its role in the study and management of Arctic territories.
\end{abstract}

KEY WORDS: Arctic region, environmental issues, integrated mapping, thematic structure of the atlas

\section{INTRODUCTION}

In the last decades, there has been a shift of emphasis in research to Arctic environmental issues and environmental safety, which is associated with environmental degradation in the region and awareness of its importance in today's global development. The United Nations Environment Program (UNEP) highlights the following key environmental issues in the Arctic region: climate change and melting Arctic sea ice; pollution of waters of the northern seas by oil discharge and chemical compounds, as well as by maritime transport; and the reduction of populations of Arctic animals and their habitats change.

Environmental problems of the Arctic have a high probability to grow from regional to global. The reason for the trends observed is the natural geographical features of the region, its high ecological vulnerability, and negative vector of natural processes in the XXI century [Golubchikov, 1991, Agranat, 1998; Beketov, 2002, Bryzgalo, 2009, State Report..., 2009]. No less significant are the prospects for intensifying economic activity for the development of the Arctic natural resources, particularly in connection with proven large mineral resources. Provisions have been made for the future reorientation of exploration and mining of mineral resources to the continental shelf. 
The international community clearly understands the need for close integration of goals, objectives, and strategic priorities of state policies in addressing environmental problems [Morgunov, 2005; 2006]. The environmental factor, along with social and economic elements, is a key component in the models for sustainable development [Dodin, 2005]. This is especially significant for Russia, where after the collapse of the USSR, the proportion of the area of the Arctic territories and waters is approaching $60 \%$. The Arctic region is considered a raw materials region and the strategic and territorial reserve of Russia in the XXI century [Gramberg et al, 2000; Arctic: Russia's interests..., 2002, Danilov, 2006; Maritime Doctrine; A new stage..., 2007]. In the "Principles of State Policy of Russian Federation in the Arctic for the period up to 2020 and beyond", preservation of the unique ecosystems in the Arctic is listed among the major national interests. The main objectives of the state policy of the Russian Federation in the field of environmental security are specified as conservation and protection of the Arctic environment, eradication of the environmental consequences of increasing economic activity and global climate change. In his speech, V. Putin stated, "Environment of the Arctic is more valuable than oil and gas reserves".

Moreover, in science and technology, the main goal is set "to ensure a sufficient level of basic and applied research to generate knowledge and to create modern scientific and geo-information framework for management of Arctic territories..." The "Development of techniques and principles of ecological mapping of territories and waters» is part of the Arctic block of the program "Environmental Safety of Russia". The anticipated results include various environmental maps of (e.g., the environmental map of the Arctic zone of Russia, scale $1: 2500$ 000, and the Arctic Environmental Atlas).

Indeed, experience shows that the best kind of representation of spatially distributed information that could give a clear, coherent, complete, and adequate description of the Arctic environment may be provided by the Atlas Information System, i.e., AIS "Ecology of the Arctic" that would accumulate diverse information scattered across various sources, often contradictory, in a series of interlinked and coordinated thematic blocks. During the first phase, it is feasible to develop and disseminate the Atlas (Environment of the Arctic) in printed or electronic versions as part of the project subsequently carried to the AIS phase.

\section{THE PURPOSE AND PRINCIPLES OF THE ATLAS COMPILATION}

A scientific-reference atlas "Environment of the Arctic" is understood as the knowledge base of spatial-temporal information on natural and socio-economic factors of the environmental conditions, on current environmental situation, on a complex of measures to improve it; the Atlas will consist of a collection of cartographic models designed for scientific, management, economic, defense, and a wide range of educational and social activities. The Atlas will serve as a tool to implement the principle of greening of economic activity in the process of economic development, to address social problems, to raise the level of public awareness about environmental hazards, and to implement environmental ethics into practice. The Atlas is designed as an integral but independent part of the "National Arctic Atlas."

The objectives of the Atlas include: 1) description of the natural environment in the Arctic region through analytical and comprehensive maps that characterize the environment systemically (if possible), comprehensively, and in the most intricate way; 2) insurance of the relevance and accuracy of cartographic models through synthesis and interpretation of various sources (cartographic, statistical, literary) using primarily remote sensing (satellite imagery); and 3) development of maps based on modern scientific methodologies that integratenationalscientificachievementsand 
international experience; thus, it is necessary to rely on a methodology which implies international cooperation and co-creativity in the development of maps and the use of a single "cartographic language"; and 4) preparation of maps based on modern GIS technologies that allow updating, analyzing, and processing information in order to acquire new knowledge and additional data to meet current informational demand.

The development of the content of the Atlas relies on the following basic methodological principles:

1) The Arctic region is considered from the viewpoint of building a system of sustainable development that combines environmental, economic and social aspects;

2) In mapping, the priority is given to environmental aspects of development;

3) The emphasis is equally distributed, if possible, between terrestrial and marine (ocean) geosystems;

4) Given the natural and economic characteristics of the region, when using both biocentric and anthropocentric approaches in mapping, the priority is given to the biocentric approach. It defines the structure of the Atlas and the sequence of the Atlas blocks;

5) Theenvironmental aspects are considered in a close connection with socio-, cultural-, and ethnic aspects;

6) The environment of the region is represented within three temporary dimensions; i.e., a stable state associated with long-term fundamental characteristics of geosystems; the current state associated with rapidly changing natural and anthropogenic influencesand theirconsequences; a potential (predicted) state associated with forecast of results of implementation of international and national efforts aimed at optimization of the environment of the region in achieving sustainable development.
7) Use, along with qualitative, of quantitative characteristics in the representation of environmental phenomena and processes.

In order to design and create the "Environmental Atlas of the Arctic" at a high scientific and technological level, it is necessary to absorb modern achievements of science and implement a series of requirements based on the principles that have emerged in the practice of mapping studies:

- the Atlas is regarded as a body of information and knowledge gained to date in long-term and comprehensive studies of the Arctic region and as a means of research and development strategy;

- the Atlas will be developed based on the latest scientific-methodological achievements in the thematic scientific fields (geography, biology, ecology, history) and in cartography while maintaining continuity with the best national and international cartographic products;

- the Atlas will be a part of the informational system of the Arctic region of Russia. It will be created and will be used as its constantly updated cartographic and geographic sub-system.

The Atlas will address multifunctional uses; it have a versatile content, thematic completeness, geographic specificity and details, the inner unity (complementarity, consistency, and comparability of the maps), the scientific validity, and the most current information; it will be illustrative and accessible.

The Atlas will contain themes that reveal major environmental problems of the modern development in the Arctic [Russian Arctic..., 1996]. Such themes include pollution and degradation of environmental components in the context of increasing anthropogenic pressure; accumulation of waste; higher risks and costs of the development of natural resources; 
global climate change and its effect on the permafrost zone; development of severe weather, ice, and other natural processes and increasing risk and damage from these processes; and sustainable development of the region. Environmental conditions will be analyzed in a close connection with sociocultural characteristics inherent in the region.

A high variety of the maps and their large number demand balance between different thematic sections in terms of the number of maps, their scope, level of generalization, and other characteristics. The maps will represent thematic events dynamically and will reflect their historical development allowing deeper understanding of processes occurring and predict the nature of their development. Mapping of the Atlas is implemented at four spatial scales matched by appropriate map size and layout (circumpolar, Russian, regional, and local). All levels are closely linked to each other.

Development of the maps' content in the Atlas will be based on modern scientific approaches (integrated, systematic, resource inventory, regional, assessment and forecast, geo-engineering, environmental-geographical, historical, and comparative-geographic). Mapped objects and phenomena and their conditions and relations between them will be assessed and presented at three levels of generalization: analytical (representation of "homogeneous" objects within a single system of parameters), complex (representation of several interconnected phenomena or their elements, each in its own system of parameters), and synthetic (representation of isolated integral objects with their holistic properties).

\section{THE STRUCTURE AND THEMATIC CONTENT OF THE ATLAS}

The Atlas "Environment of the Arctic" includes seven parts (blocks) and consists of the following topics represented by maps, text, space and aerial images, and graphic illustrations. These blocks are described in sections presented below.

\section{Introduction}

- Environment of the Arctic in the context of sustainable development of the region and the world.

- Arctic from Space.

- Political map of the Arctic. The boundaries of the region.

- Administrative-territorial division of the Russian Arctic zone.

- General geographic maps.

- Milestones of Arctic development. Environmental impact of economic activities at different stages of development.

\section{Part I. Conditions of the natural environment}

The Arctic Ocean

- Bathymetry. Natural-depth and naturalaltitudinal zonation. Continental shelf.

- Bottom sediments.

- Surface currents. Salinity of the surface layer (summer, winter). The density of water. Hydrochemical characteristics.

- Winds. Tides and surges.

- Ice conditions.

- Continental runoff into the Arctic Ocean.

Landscapes

- Types of terrestrial landscapes.

- Environmental landscape potential. Seasonal landscape dynamics.

- Stability of landscapes to main anthropogenic impacts. The period of regeneration of Arctic landscapes after anthropogenic disturbance in comparison with other zonal types.

- Shelf landscapes. 
The geological environment and landscape

- Geology.

- Neotectonics. Seismicity.

- Quaternary sediments. Lithology.

- Orography. Modern relief forming processes.

- Geochemical landscapes.

- Mineral resources. Reserves.

Climate

- Types of climate. Climate severity.

- The total annual solar radiation.

- Temperature regime (the number of days with temperatures below $-30^{\circ} \mathrm{C}$; the absolute minimum air temperature; the maximum air temperature; the absolute minimum air temperature; the average annual air temperature).

- The sum of daily mean above $10^{\circ} \mathrm{C}$ air temperatures.

- The number of days when temperature rises above $0^{\circ} \mathrm{C}$.

- Wind regime (wind speed and direction; wind pattern).

- Rainfall (annual precipitation; distribution by the seasons).

- Snow cover (dates of formation and disappearance of stable snow cover; the average number of days with snow cover; snow cover depth).

- Bioclimatic zonation.

Surface waters

- Hydrographic network. Hydrological regions.

- Hydrological regime. The maximum and average river flow. The intra-flow distribution.
- Hydrochemical map.

- Solid discharge. River turbidity.

- Percent lake area.

- Percent wetland area.

- Self-purification properties of surface water.

Permafrost

- Types of permafrost, depth, temperature regime. Seasonal freezing and thawing of rocks. Permafrost terrain.

- Glaciers and mudslides.

Soil cover

- Types, structure, depth, soil age.

- Lithogeochemical origin of landscapes.

- Soil-geochemical conditions.

Flora and fauna

- Ecoregions.

- Biomes. Biodiversity. The coefficient of biodiversity uniqueness.

- Vegetation cover. Floristic zonation. Boundaries of forest vegetation.

- Unique and rare species and plant communities. Species in the Endangered Species List.

- Phytomass stocks. Mortmass stocks. Plant communities Productivity. Geochemical cycling of matter.

- The population of terrestrial and marine vertebrates. Faunistic zonation.

- Mammals.

- Birds. Migration routes. Rare and endangered species. Species in the Endangered Species List. 
- Freshwaterfish. Rare and endangered species. Species in the Endangered Species List.

- Entomofauna.

- Biota of the ocean. Biological productivity of waters. Marine mammals. Rookeries. Colonies of birds. The main commercial fish. Salmon spawning grounds.

- Productivity and biomass of biocenoses.

\section{Part 2. Adverse and hazardous natural phenomena and processes}

- Earthquakes.

- Hazardous geomorphologic processes (frost heave, thermokarst, solifluction, landslides, etc.). Percent affected area.

- Avalanches and mudflows. Avalanche hazardous areas (potential volume and height of the fall of avalanches). Mudflows with an estimate of the maximum discharge and volume of mudflow mass. The degree of risk. Areas of greatest risk of mudflows.

- Severe and hazardous weather in warm and cold periods (thunderstorm, hail, strong wind, fog, storm, etc.).

- Hazardous hydrological events (floods, high-water, catastrophic floods, icing). Ice gorges and jams on rivers. Dates and frequency of formation.

- Fire hazard of vegetation cover (tundra communities, dwarf-cedar thickets, neartundra sparse forest). Potential fire hazardous areas. Risk of landscape fires resulting from accidents on oil and gas pipelines; at factories for processing and storage of gas, oil, and oil products; and in mining.

- Biological adverse events (distribution and seasonal occurrence of gnat, etc.).

- Natural risk and losses. Potential natural disasters zonation.
- System of a comprehensive safety of the public and the territory of the Arctic zone. The complex rescue centers of the Ministry of Emergency Situations.

\section{Part 3. Anthropogenic factors of the environmental conditions}

Anthropogenic impacts

- General economic map.

- Energy sector: the impact on the natural environment.

- Military and defense industry: the impact on the natural environment. Nuclear explosions and their aftermath.

- Objects that are origins of technogenic emergency situations (Nuclear Power Stations Kola, Bilibino, etc.).

- Mining, ore mining and smelting, oil mining, oil processing, and pulp and paper facilities and their impact on the natural environment. Toxic waste and emissions. Accidents and their consequences.

- Fishing industry: the impact on the natural environment.

- Agricultural areas. Agricultural development of landscapes. Land-use patterns. Natural grasslands. Reindeer herding (pasture load).

\section{Animal husbandry}

- Hunting and fishing industry: examples of the unbalanced nature management.

- Risks of oil and gas pipeline transportation. Pipelines accidents.

- Impact of transport.

- Waste and its volume by sector (industrial, agricultural, and municipal). Major landfills of solid municipal and industrial waste. Waste drum storage. 
- Production, import, and use of toxic and radioactive waste. Disposal of nuclear waste. Sea ports for operations with nuclear materials.

- Anthropogenic pressures on the landscape.

The consequences of anthropogenic impacts

- Cross-border western pollution transfer. Emissions of pollutants into the atmosphere. Emissions structure. Acid rain.

- Pollution of marine waters: river and sea fleet, continental runoff, extraction on the continental shelf, long-range transport of pollution by sea currents, dead zones of synthetic surfactants (SS).

- Pollution of snow.

- Degradation and the current state of permafrost.

- Water and wind erosion. Ravine erosion.

- Contamination of surface waters. Chemical and biological contamination. Petrochemical pollution. Cases of extreme water pollution. Accidental pollution of surface waters. The volume of wastewater discharged from stationary sources.

- Land disturbance.

- Distribution of main pollutants by natural and anthropogenic components: oil and gas, ore and ore-bearing rocks, soil and sediment, biochemical, water, ice and snow, air and gaseous dust-like, in the food chains (lichen-reindeer-humans, mushrooms- and berries-humans, etc.).

- Pesticides in soils.

- Soil contamination with heavy metals.

- Radioactive contamination. Radioactive waste. Burial sites of radioactive waste.

- Biodiversity reduction.
- Biological contaminants (the emergence of new species of marine flora and fauna).

- Electromagnetic pollution.

- Arctic tourism. Risks, taking into account the environmental impacts of tourism development.

\section{Part 4. The state of the natural environment}

\section{Circumpolar Arctic.}

- Environmental problems in the Arctic at the present time.

- Climate change.

- The dynamics of the ozone hole.

- The melting of Arctic ice.

- Permafrost degradation.

- Loss of biodiversity.

Arctic region of Russia

- Climate change.

- Dynamics of Arctic sea ice.

- Zones of sustainable long-term air pollution. Urban air pollution.

- State of the geological environment.

- State of groundwater.

- The current state of permafrost.

- State of river channels.

- Surface water quality.

- Soil salinization.

- Hydromorphism and soil paludification.

- Soil-geochemical conditions.

- Conditions of radionuclide migration. 
- Vegetation state.

- Fauna degradation.

- Stability and transformation of ecosystems

- Environmental-geographical situation.

Arctic territories of environmental concern

- Environmental conditions in the impacted areas (trouble sites): Norilsk RJSC "Norilsk nickel", Krasnoyarsk Aluminum Plant, Murmansk sites, etc.).

\section{Sea and Coastal area}

- Most contaminated areas of the seas. Barents Sea (industrial pollution, consequences of the "cold war", reduction of fish stocks, etc.).

- The state of environment of the coastal zone.

\section{Monitoring of the natural environment}

- The role of Arctic monitoring in the global monitoring. Space Arctic monitoring. Observation stations for environmental assessment parameters. Monitoring of natural disasters. International cooperation.

\section{Part 5. Population and Environment}

- Anthropoecosystems.

- Comfort (discomfort) of living conditions.

- Demographic-ecological map.

- Distribution of population. Density (physical and social) of population. Population of urban settlements

- Functional types of settlements.

- Cultural landscapes.

- Employment in industry and agriculture

- Land use. Types of crops.
- Land use conflicts.

- The share of environmental crimes in the structure of crime.

- Religion and the socio-environmental ethics.

- Cultural and ethnic diversity of the population. Indigenous peoples. Indigenous minorities and other ethnic groups. The number and distribution. The overall mortality rate. The main economic-cultural types. Traditional forms of agriculture and natural resources management. Territories of traditional nature management. Traditional environmental knowledge and behaviors.

- Quality of life.

- Types of food. Northern food habits.

- Sanitary-environmental conditions. Natural focal diseases. Biogeochemical endemic diseases.

- Public health. Sick rate. The incidence of certain diseases. Social diseases.

- Loss of biotic potential of the population.

- Recreation potential of the territory. Local health enterprises (sanatoriums, resorts, preventative clinics).

\section{Part 6. Optimization of the Arctic environment and sustainable development}

- System of sustainable (environmental) management and natural resources conservation.

- The natural and historical-cultural heritage. Specially protected natural areas. Reserves. Wrangel Island. Ust Lensky, Taimyr, Great Arctic, Purinsky, Severozemelsky, Gydansky, Nizhneobsky, Nenets, Kandalaksha, Franz Josef Land, and Murmansk reserves. Wildlife refuges. Nature Monuments. 
- Measures to preserve ethnic and cultural environment.

- Environmental organizations involved in Arctic issues. Youth and children's associations engaged in environmental issues.

- Computerization of environmental policy (creation of information-analytical and other industries) to provide information to the public in order to optimize the human living environment and processes occurring in nature and society.

- Federal and regional programs and projects to improve environmental conditions in the Arctic.

- Alternative options for the development of the Arctic zone of Russia: from the current predatory super-economics to traditional land use. Socio-economicenvironmental models for sustainable development in the region.

\section{Part 7. The Arctic - the territory of international dialogue}

\section{Circumpolar Arctic}

- Sustainable development of the Arctic territory - a strategy for international dialogue and cooperation.

- International OrganizationforCooperation in the Arctic.

- International environmental programs.

- Large investment projects.

- Searching for new aspects of international cooperation and approval of the Arctic as a zone of peace and cooperation.

- Scenarios for minimizing the environmental impact of economic development in the Arctic in the context of international cooperation.

\section{SECTIONS DESCRIPTION}

The task of the introductory section is to show the global environmental role of the region in the human civilization and to reflect the increasing intensification of human impact at different stages of development of the region and the need to transition to sustainable development as the only reasonable alternative. The position of the Arctic in geographic space and in modern geopolitical space is reflected by a series of general geographical and political maps and satellite images of the world and Russia.

Part I."Conditions of the natural environment", will include eight sections. The first section is devoted to one of the largest ecosystems in the region, the Arctic Ocean. This chapter contains bathymetric maps and maps on the natural altitudinal zonation of the ocean and on the main hydrological, geochemical, and meteorological characteristics. The next section, "Landscapes", is devoted to the types of terrestrial landscapes. This section will provide environmental characteristics of the landscapes, e.g., environmental potential, resistance to basic types of impact, period of regeneration after anthropogenic disturbances in comparison with other zonal landscape types, etc. The latter component will reflect the high vulnerability of arctic landscapes. A separate map is dedicated to the landscapes of the shelf.

Other sections of this chapter will present the main features of the region's natural environment (geological, climatic, hydrological, permafrost, and soil-biotic) that characterize the state and specific features of the functioning of Arctic ecosystems. Figures 1 and 2 show fragments of two maps of the section: "Self-purification of surface water" and "Soil-geochemical conditions".

Much attention will be given to plant and animal life in the Arctic. The section will open with the map "Ecoregions" which will show the territorial ecological terrestrial units isolated based on features of the natural terrestrial communities. This territorial grid is used in the practice of 


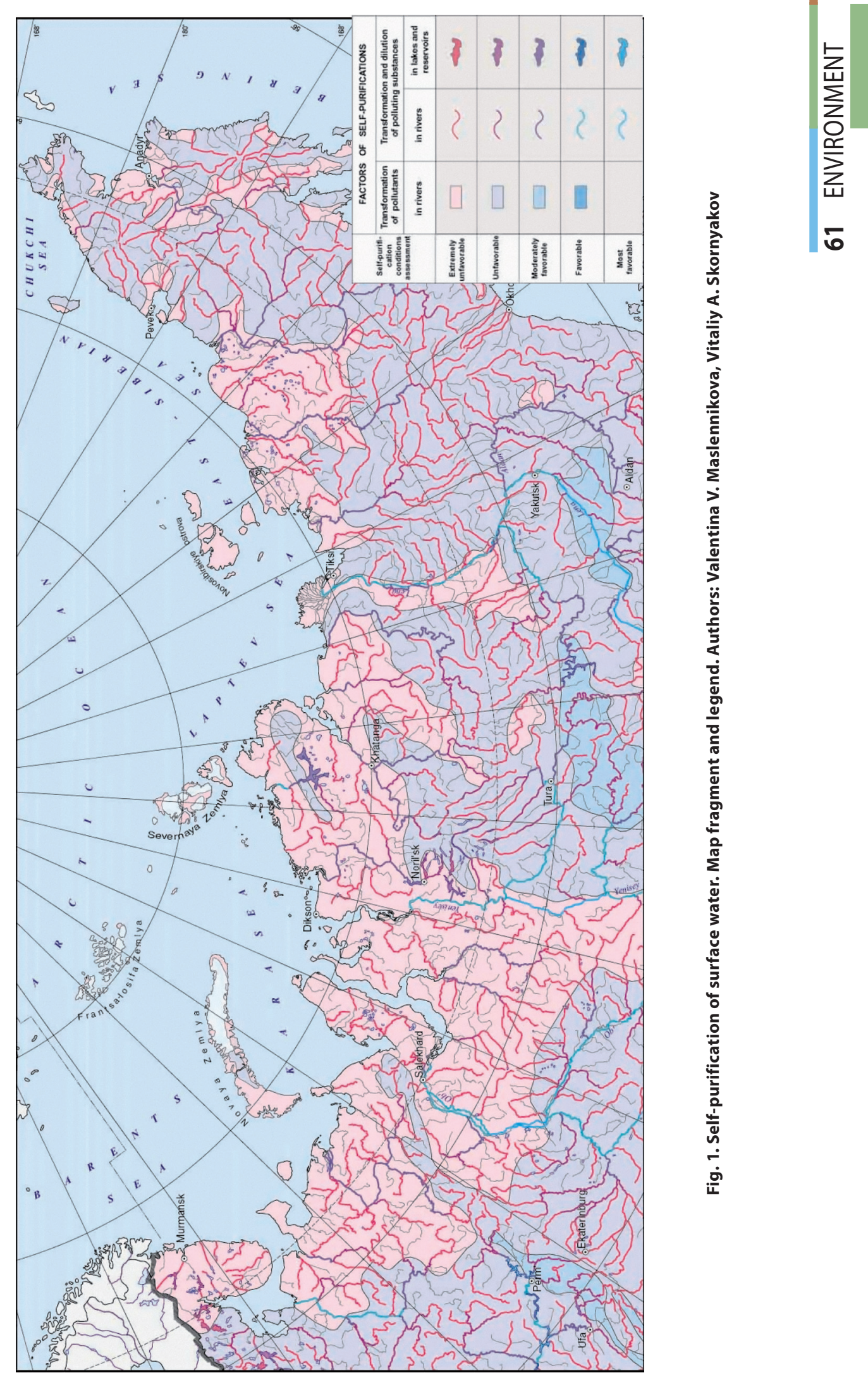




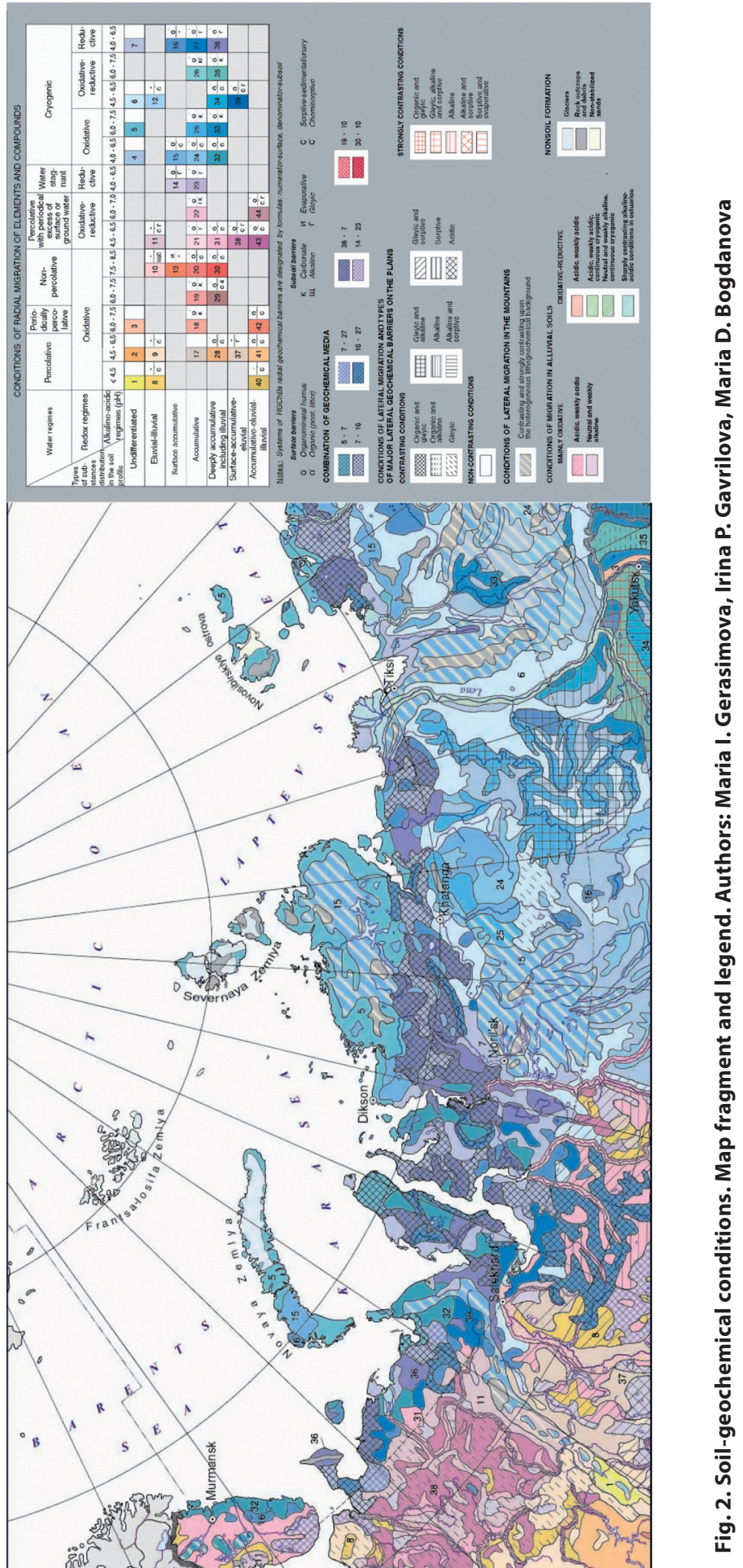


international studies to assess and compare the richness of biodiversity of territories and to assess the representativeness of networks of nature reserves, including their plant communities and animal populations. The integrated biogeographic map "Biomes" will reflect assessment of biodiversity, with emphasis on its uniqueness. Several maps will show vegetation of the region and the boundaries of forest vegetation and its dynamics under global warming. The information is extremely important for the delineation of the geographical boundaries in the Arctic zone at the southern limits of the tundra. Characteristics of vegetation distribution will be complemented by the ranges of unique and rare plant species and plant communities. The species included in the Endangered Species List of Russia and the regional Endangered Species Lists will be specifically highlighted. The next group of maps (phytomass stocks, mortmass stocks, productivity, etc.) will describe the production processes of vegetation, which allows assessment of the role of ecosystems in the biosphere.

The detailed characteristic of the animal world will include a map of the population of animals broken into individual classes, and ranges of distribution of rare and endangered species, including those in the Endangered Species List.

A separate group of maps will be devoted to thefauna of oceanic waters:marine mammals, birds, and fish. This group will be concluded with a map on productivity and biomass of biocenoses. More complete detailed characteristics of the natural components will be presented in a comprehensive National Atlas of the Arctic.

Part 2. "Adverse and hazardous natural phenomena and processes," is particularly important; it will describe adverse and dangerous natural phenomena and processes in the life of the region's population at the background of the overall predominantly uncomfortable conditions. The maps of this section will show a wide spectrum of natural (and partially, naturalanthropogenic) phenomena of different origin, e.g., geological, meteorological, biological, etc. that are able to change sharply environmental situation from adverse to catastrophic. A comprehensive zoning map on the risks of natural disaster situations will show the risks and losses from the potential impact of these factors, differentiated by region. The section will end with a description of a comprehensive system of measures to ensure safe living conditions in the region under the auspices of the Ministry of Emergency Situations.

Part 3. "Anthropogenic factors of the environmental conditions", will consist of two sections. The first section will show the sources of anthropogenic impacts and their consequences. The section will open with a general economic map on the economic performance of the population, the main centers of economic development, and the types of sources of human impact. Further sections will have a series of detailed analytical and comprehensive maps showing the adverse factors in industries, transportation facilities and structures, agriculture, and hunting and fishing. Because the Arctic has long been used for nuclear testing and dumping of radioactive waste, these themes will be presented on separate maps. The section will conclude with maps on assessment of anthropogenic load on landscapes.

The second section will reflect the effects of anthropogenic impacts on the natural environment in the form of various kinds of environmental pollution (pollution of the Arctic sea, air pollution) and intensification of adverse natural and natural-anthropogenic processes (erosion, disturbance of land, loss of biodiversity, etc.). A distinctive feature of this section will be the inclusion of a sufficiently large number of maps with quantitative characteristics.

Part 4. "The state of the natural environment", will present the environment at three levels. The circumpolar Arctic will include 
contemporary environmental problems on a region-wide and the global scales. More detailed characteristic will be provided for the Arctic region of Russia. This part will include a map on the natural environments and several synthetic maps, showing the ability of ecosystems to withstand adverse impacts and assessment of ecological and geographical conditions in the region based on bio- and anthropocentric approaches. The series of maps on a larger scale (local level) will describe challenging ecological conditions of impacted areas and sea and the coastal areas of major concern.

The logical conclusion of the section will be a section devoted to monitoring of the natural environment and, in particular, to ecological monitoring and international cooperation in this practical field of ecology.

One of the main parts of the Atlas, Part 5 "Population and Environment," will be devoted to population, the environment and its characteristics, and forms of existence of the population engaged in various industries. The chapter will start with a conceptual map, "Anthropoecosystems" that will represent spatial divisions of the human environment isolated according to the similarity of natural, socio-economic, industrial, environmental, hygienic, and cultural-social conditions of life [Prokhorov, 2010]. Characteristics of the population of the Arctic region, i.e., distribution, density, and employment in industry and agriculture) will be displayed in a number of maps. An important place in the section is assigned to a group of maps showing land use, crop types, and environmental conflicts in natural resources management.

Appreciation of the importance of cultural and ethnic aspects that are not of lesser importance for solving problems of environment and sustainable development than the progress in science, technology, and economy, calls for the inclusion in the section of a collection of maps covering the role of the Arctic indigenous peoples in the transformation of the environmental situation in the region [Petrov, 1998; Krasovskaya, 1999; Klokov, 2002].

An integral part of the characteristics of the population, i.e., ethological environmental, will be reflected in the sections "Religion and the socio-environmental ethics", "Traditional environmental knowledge and behaviors", and "The share of environmental crimes in the structure of crime", Quality of life, as well as public health, will be covered in about a dozen maps.

Part 6. "Optimization of the Arctic environment and sustainable development," [Filippov and Zhukov, 2006] will highlight the contemporary view (concept) on the solution of major environmental problems in the region, on the transition to sustainable development through design and recommendation of plans, projects, and programs to improve environmental conditions. Awareness and involvement of population has major importance in the implementation of such programs. The maps will reflect the activities of national and regional environmental organizations involved in Arctic issues, with youth and children associations shown separately. Informatization issues on environmental policy as an important component of the modern process of environmental attitude and behavioral patterns in society is closely associated with policy issues.

The concluding Part 7 "The Arctic - the territory of international dialogue," is dictated by the considerations of the need for close international cooperation on issues of environmentally sound development in the Arctic, as both moral and environmental imperative for further progress [Smorchkova, 2003; International Arctic Forum].

\section{CONCLUSION}

The Atlas is a compilation of vast information for the study of environmental conditions in the Arctic aimed at optimization of the development and implementation of sound national environmental policy, 
environmental education, education of general public, and improvement of the environmental culture. The Atlas will be of great value in representation of the environmental conditions in Russia and the world at the global, sub-global, and regional levels.

The most important methodological feature of the Atlas is a comprehensive systematic representation of environmental relationships and interactions in the system "nature-humans-society-industry",Anotherits feature is the focus on solving the problems of sustainable development in the Arctic by providing assurance and leadership in defining strategies and tactics for its implementation. The Atlas will be the basis of socio-economic development, of environmental and national security of Russia, and of competent evidencesupported dialogue with foreign partners.

The Atlas will serve as a starting point and the information basis for the development of the AIS "Environment of the Arctic".

\section{REFERENCES}

1. A new stage in the development of the Arctic // Russian Federation today. (2007) № 17.

2. Agranat, G.A. (1998) Development of the North: A Global Perspective // Achievements of science and technology. Ser. geogr. foreign countries. Moscow: VINITI. Vol. 15. 148 p.

3. Air pollution in the Russian Arctic // Arctic today. http://arctictoday.ru/region/ ecology/200000056

4. Atlas of biological diversity of seas and coasts of the Russian Arctic. (2011) Moscow: WWF Russia. 64 p.

5. Beketov, N.V. (2002) Greening the investment policy in the Arctic // Problems of the modern economy. № 1 (5).

6. Bryzgalo, N.V. (2009) Anthropogenic transformation of the hydrological and ecological state of rivers of the Russian Arctic // Water Resources. № 3. Vol. 36. Pp. 277-288.

7. Golubchikov, Yu.N. (1991) The polar alternative // Energy: Economics, technology, and ecology. № 12. pp 69-74.

8. Gramberg, I.S., Dolin, D.A., Laverov N.P., et al (2000) The Arctic on the threshold of the third millennium. St. Petersburg: Publishing House "Nauka", 248 p.

9. Danilov, A.I. (2006) Russia's return to the Arctic // Earth and Universe. № 1. pp 3-12.

10. Dodin, D.A. 2005. Sustainable development in the Arctic. (Problems and perspecitves). St. Petersburg: Publishing House "Nauka", 248 p.

11. Filippov, V.V., Zhukov, M.A. (2006) Problems of economic development of the Arctic zone of the Russian Federation. NEP-XXI century. Science Industry Economics. № 2. pp. 19-22. 
12. International Arctic Forum "The Arctic - the Territory of Dialogue». http://forsmi.ru/ node/22107.

13. Klokov, K.B. (2002). Ethnocultural aspects of nature of the Arctic region of Russia // Geography and Natural Resources. № 4. pp. 23-29.

14. Krasovskaya, T.M. (1999) Ecological and economic problems of Northern Russia // Vestnik Mosk. Univ. Ser. 5 Geography. № 4. pp. 25-29.

15. Marine Doctrine of the Russian Federation for the period till 2020. http://www.scrf.gov.ru/ documents/34.html.

16. Morgunov, B.A. (2005) Environmental constraints in making strategic decisions for the development of the Russian Arctic // Proceedings of the Rus. Academy of Sciences. Ser. Geogr. №; pp. 48-57.

17. Morgunov, B.A. (2006) Methodology for incorporating environmental considerations into the process of developing strategies for sustainable development of the Arctic zone of Russia. Abstract Thesis. of doctoral degree. geogr. science. St. Petersburg.

18. Petrov, Yu.D. (1998) Arctic Indigenous Peoples: public policy and regional practice. Moscow, $207 \mathrm{p}$.

19. Pollution of the Russian Arctic // Arctic today. http://arctictoday.ru/region/ ecology/200000055

20. Prokhorov, B.B. (2010) Human Ecology. Moscow: Publishing Center "Academia", 320 p.

21. Russian Arctic on the verge of disaster / A.V. Yablokov (Ed.). (1996) Nauka. 208 p.

22. Smorchkova, V.I. (2003) The Arctic is the region of peace and global cooperation. Moscow: RAGS. $246 \mathrm{p}$

23. State Report "On the state and Environmental Protection of the Russian Federation in $2009^{\prime \prime}$

24. The Arctic: Russia's interests and international environment for their implementation / Yu.G. Barsegov, V.A. Korzun, I.M. Mogilev et al (Eds.) (2002) Moscow: Nauka. 356 p. 


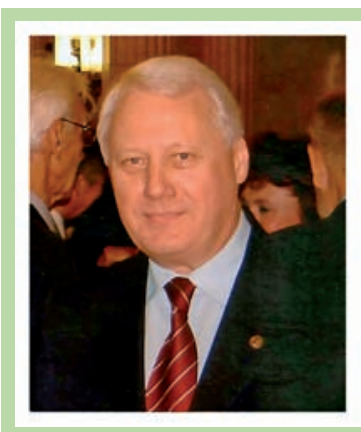

Nikolay S. Kasimov received his Ph.D. (geography) in 1972 and his Doctor of Science degree in 1983. Since 1987, he has been professor and Head of the Department of Landscape Geochemistry and Soil Geography. In 1990, he became Dean of the Faculty of Geography, Lomonosov Moscow State University. His current research interests are fundamentals of landscape geochemistry, paleogeochemistry, and geochemistry of urban and aquatic landscapes. He is the author of about 300 scientific works, including, Ecogeochemistry of Urban Landscapes, 1995 (author and editor); Landscape Geochemistry, 1999 (co-author A.I. Perel'man), Biogeochemistry 004 (co-author V.N. Bashkin), and Oil and Environment of Kaliningrad Region, 2008 (editor and author).

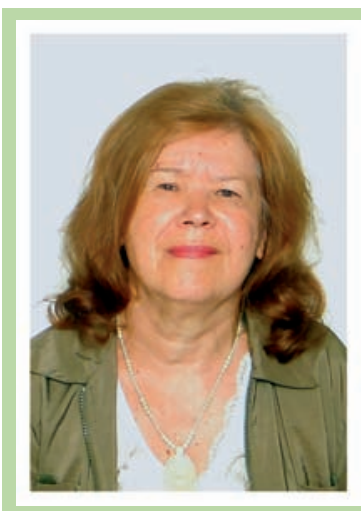

Tatyana V. Kotova graduated from the Department of Geodesy and Cartography (now the Department of Cartography and Geoinformatics) of the Faculty of Geography, Lomonosov Moscow State University, in 1961, and has been with the Faculty of Geography since 1964. She received her Ph.D. in geographical studies in 1976. At present she is leading researcher of the Laboratory of Integrated Mapping (Faculty of Geography, Moscow State University). The main area of research interests is integrated thematic, biogeographic, and ecological mapping. She published over 170 papers and participated in creation of complex cartographic products as a managing editor, an editor, or an author of individual chapters (World Atlas of Resources and Environment, 1998; Atlas of the Khanty-Mansiysk Autonomous Region Ugra 2004, 2006; Atlas of the Kuril Islands, 2009; The National Atlas of Russia, 2007; 2009; etc.).

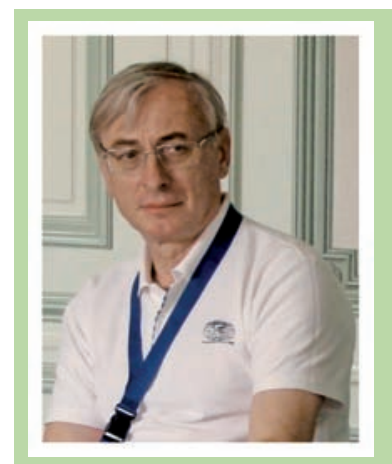

Vladimir S. Tikunov is Professor, Head of the Laboratory of Integrated Mapping, Faculty of Geography, Lomonosov Moscow State University; Director of the Center of the World Data System for Geography. His research results were implemented in a number of thematic maps and atlases: the National Atlas of Russia (3 volumes) (Editor in Chief), the Environmental Atlas of Russia, the Atlas of the socio-economic development of Russia, the Atlas of the Khanty-Mansi Autonomous Region - Ugra, etc. Prof. Tikunov received D.N. Anuchin award for his work on mathematical and cartographic modeling and the Russian Federation Award in Science and Technology for the development of environmental and natural resource atlases of Russia. He was Vice-President and is currently Chairman of the International Cartographic Association and a member of the Commission on Geographic Information Science of the International Geographical Union. Prof. Tikunov is a leader of a number of Russian and international projects. He is also a member of the editorial boards of nine Russian and international scientific journals. Prof. Tikunov delivered a number of lecture courses at national and foreign universities. He organized annual international conferences InterCarto-InterGIS "Sustainable Development of Territories: GIS theory and practical implementation" that have been taking place in Russia and abroad since 1994. He published over 500 works, including 14 monographs, textbooks, and instructional materials in 28 countries and in 14 anguages. 